\title{
Impact of community based, specialist palliative care teams on hospitalisations and emergency department visits late in life and hospital deaths: a pooled analysis
}

\author{
OPEN ACCESS
}

\author{
Hsien Seow associate professor ${ }^{1}$, Kevin Brazil professor of palliative care ${ }^{2}$, Jonathan Sussman \\ associate professor ${ }^{1}$, José Pereira head of division of palliative medicine ${ }^{3}$, Denise Marshall associate \\ professor $^{4}$, Peter C Austin professor ${ }^{5}$, Amna Husain associate professor ${ }^{6}$, Jagadish Rangrej senior \\ biostatistician $^{7}$, Lisa Barbera associate professor ${ }^{8}$
}

${ }^{1}$ Department of Oncology, McMaster University, Hamilton, Ontario L8V 5C2, Canada; ${ }^{2}$ School of Nursing and Midwifery, Queen's University Belfast, Belfast, UK; ${ }^{3}$ Division of Palliative Care, Faculty of Medicine, University of Ottawa, Ottawa, Ontario, Canada; ${ }^{4}$ Department of Family Medicine, McMaster University, Hamilton, Ontario, Canada; ${ }^{5}$ Institute for Health Policy, Management and Evaluation, Dalla Lana School of Public Health, University of Toronto, Toronto, Ontario, Canada; ${ }^{6}$ Department of Family and Community Medicine, University of Toronto, Toronto, Ontario, Canada; ${ }^{7}$ Institute for Clinical Evaluative Sciences, Toronto, Ontario, Canada; ${ }^{8}$ Department of Radiation Oncology, Institute of Health Policy, Management and Evaluation, University of Toronto, Toronto, Ontario, Canada

\begin{abstract}
Objective To determine the pooled effect of exposure to one of 11 specialist palliative care teams providing services in patients' homes.

Design Pooled analysis of a retrospective cohort study.

Setting Ontario, Canada.

Participants 3109 patients who received care from specialist palliative care teams in 2009-11 (exposed) matched by propensity score to 3109 patients who received usual care (unexposed).

Intervention The palliative care teams studied served different geographies and varied in team composition and size but had the same core team members and role: a core group of palliative care physicians, nurses, and family physicians who provide integrated palliative care to patients in their homes. The teams' role was to manage symptoms, provide education and care, coordinate services, and be available without interruption regardless of time or day.
\end{abstract}

Main outcome measures Patients (a) being in hospital in the last two weeks of life; $(b)$ having an emergency department visit in the last two weeks of life; or $(c)$ dying in hospital.

Results In both exposed and unexposed groups, about $80 \%$ had cancer and $78 \%$ received end of life homecare services for the same average duration. Across all palliative care teams, 970 (31.2\%) of the exposed group were in hospital and 896 (28.9\%) had an emergency department visit in the last two weeks of life respectively, compared with 1219 (39.3\%) and 1070 (34.5\%) of the unexposed group $(\mathrm{P}<0.001)$. The pooled relative risks of being in hospital and having an emergency department visit in late life comparing exposed versus unexposed were
0.68 ( $95 \%$ confidence interval 0.61 to 0.76 ) and 0.77 (0.69 to 0.86$)$ respectively. Fewer exposed than unexposed patients died in hospital (503 (16.2\%) v 887 (28.6\%), $\mathrm{P}<0.001)$, and the pooled relative risk of dying in hospital was 0.46 (0.40 to 0.52$)$.

Conclusions Community based specialist palliative care teams, despite variation in team composition and geographies, were effective at reducing acute care use and hospital deaths at the end of life.

\section{Introduction}

Home based palliative care teams are meant to help patients manage symptoms, improve quality of life, and prevent avoidable hospitalisations, which are documented issues at end of life. ${ }^{1-3}$ Moreover, policy makers internationally want to deliver integrated palliative care in the home and community, since many patients prefer to be cared for at home, community care is often less expensive than hospital care, and acute care hospitals are overwhelmed. ${ }^{45}$ However, policy makers are unsure of optimal models of care delivery based on interdisciplinary teams. Although studies have evaluated specialist palliative care teams in hospitals, ${ }^{6-8}$ only nine randomised controlled trials specifically investigated specialist teams in the community. ${ }^{9-17}$ The community based teams studied in these trials involved a core group of interdisciplinary team members, specifically palliative care physicians, nurses, and family physicians who provide integrated palliative care to patients in their homes. A common role of the teams was to manage symptoms, provide education, coordinate care, and provide additional or enhanced support and care. Teams were 
also available to care providers, patient, and family $24 / 7$ (available without interruption regardless of time or day). However, variations existed within core team members, such as the extent of involvement of the family physicians, ranging from minimal (such as a single consultation) to extensive (such as substitution of usual family physician with palliative care physician) depending on the team. In addition, teams may have included other members such as a psychosocial counsellor or social worker, varying their team compositions.

While the nine community based trials of specialist palliative care teams consistently reported improved symptom management, satisfaction, and quality of life, ${ }^{9-12}{ }^{14-16}$ the evidence for reducing hospital and emergency department visits was mixed. Three trials demonstrated that patients cared for by specialist teams had significantly fewer hospitalisations or emergency department visits compared with usual care, ${ }^{10} 1115$ whereas four trials did not. ${ }^{9} 131416$ Three trials also found that specialist teams significantly increased the likelihood of patients dying at home, ${ }^{10}{ }^{13}$ but one meta-analysis (examining community based, specialist, palliative care teams providing nursing services) found inconclusive evidence for the same outcome. ${ }^{18}$ Variations among the teams in the nine trials-including the health financing system, team size, and team composition - may have contributed to the mixed evidence, but this has not been researched. Thus, research has not clearly explained why some teams reduced acute care use while others did not.

A natural experiment exists in Ontario, Canada, where several regions have independently developed their own community based, specialist, palliative care teams. These different palliative care teams serve different catchment areas, vary in team composition, but have the same core team members and are within the same health financing system. Thus, they represent a unique opportunity to assess the generalisability of effectiveness of specialist palliative care teams in real world conditions. Specifically, this study investigates the pooled association of reducing use of acute care late in life and hospital death among those exposed to one of several community based specialist palliative care teams compared with usual care in the community.

\section{Methods}

\section{Study design}

Linking administrative databases, we conducted a retrospective cohort study in Ontario, Canada, during 2009-11. To reduce confounding due to measured covariates when estimating the effect of exposure to a specialist team, patients treated by each of 11 teams were matched to similar patients not treated by any team (usual care) using propensity score methods. The effect of each of the 11 teams was estimated separately and also pooled to obtain an overall team effect.

\section{Study setting}

Most home based palliative care in Ontario is delivered by the public homecare system without involvement from palliative care teams (referred to in this study as usual care). Usual care can be fragmented, inconsistent, and of variable quality. ${ }^{19} \mathrm{On}$ referral to the public homecare agency, a patient is identified as needing palliative care by a case manager. The homecare agency coordinates care and contracts the delivery of services, mainly nursing and personal support at end of life, to multiple service provider organisations. ${ }^{20}$ Patients are often treated by different service provider organisations with little coordination between them. The palliative care training of the homecare workers is highly variable. ${ }^{21}$ In Ontario $68 \%$ of cancer patients receive some homecare services in the last six months of life,,$^{22}$ and $62 \%$ of those patients received end of life homecare services at some point, two thirds for less than three months before death. ${ }^{23}$ Contacting providers and receiving care after office hours or on weekends is difficult.

Most family physicians provide care independently of homecare and rarely make home visits. ${ }^{24}$ Research has shown that, among Ontarian cancer patients, $85 \%$ saw a family physicians at least once while receiving end of life homecare services, for a median of 0.75 family physician visits/week ${ }^{25}$ Further, $24 \%$ had a physician house call in the last two weeks of life. ${ }^{22}$ However, family physician training in palliative care is highly variable, and palliative care physicians are involved in care in an uneven or limited capacity, since most are employed in a hospital setting to serve in an inpatient palliative care unit rather than in the community. Therefore, "usual care" in Ontario is a poorly integrated system.

Ontario only has about 24 residential hospices for the entire province, each with about 10 beds. Thus, there is limited capacity in the system to accommodate patients dying in a residential hospice bed. Indeed, the rate of hospital deaths in Ontario is $65 \%,{ }^{26}$ compared with $45 \%$ in the US ${ }^{27}$ and $65 \%$ in the $\mathrm{UK}^{28}$

In contrast, in regions where specialist palliative care teams were available, patients were referred to a team by a provider from the hospital, family physician's office, cancer centre, or homecare agency based on clinical factors, functional decline, and expected prognosis of less than six months. The specialist team would then visit the home to determine eligibility, care plan, and how often to visit and call the patient afterwards, caring for them until death.

\section{Selection criteria \\ Intervention teams and exposed patients}

To identify Ontario teams for inclusion in our study, we included formal palliative care specialist teams that met the following criteria: (a) provided interdisciplinary, home based, palliative care; $(b)$ were the only such team in their respective region; $(c)$ had little or no change in staffing between 2009 until 2012; $(d)$ had broad admission criteria not limited to one disease (such as cancer); $(e)$ admitted more than 50 patients a year; $(f)$ were available to patients $24 / 7$; and $(g)$ had the same core members of their team as the past randomised trials. However, team size, team members, geography, and referral capacity could vary. Across the province, 11 teams met these criteria, and their patients served were eligible for inclusion. Patients were excluded if they were alive after fiscal year 2011, were $<18$ years old, or had an invalid or missing provincial health insurance number.

\section{Comparison regions and unexposed patients}

We a priori chose two approaches to identify control groups exposed to usual care.

Historical-For teams beginning after 2009 (teams 1 to 6), exposed decedents were assigned a match from the pool of decedents within the same health region in an earlier period, fiscal years 2007-09, so factors related to health system delivery were the same. No other major policy or organisational changes related to palliative care occurred between 2007 and 2011 in these regions, except for the team development after 2009 , confirmed by policy review and interviews with the team administrators. 
Geographical-For teams starting before 2009 (teams 7 to 11) exposed decedents were assigned a match from the pool of decedents from a neighbouring region that was similar in size, geography, and access to services during the same study period (fiscal years 2009-11) but did not have a specialist palliative care team available.. This second approach was used because, based on anecdotal evidence from clinical providers of these mature teams, the usual care system in their region was "contaminated": teams had developed sufficiently to build key relationships and increase palliative care knowledge in usual care providers, allowing them to handle more basic palliative care needs on their own-which meant the teams were getting referred more complex and symptomatic patients. This created a selection bias in the unexposed cohort pool within their regions which were unmeasured. Thus, we chose a similarly resourced neighbouring region that did not have a specialist team, to reduce bias and keep the control group's exposure to "usual care" consistent across teams for generalisability.

\section{Data sources}

Each team provided a list of patients admitted to the intervention team during fiscal years 2009-11. This list was linked to multiple administrative databases via a unique, encrypted, provincial health insurance number. We used the provincial Vital Statistics database to confirm date of death, age at death, and sex. We used the Discharge Abstract Database to determine hospital admissions or hospital death (which excluded the hospital's palliative care unit), as well as comorbidity score weight, and presence of cancer condition. We also used National Ambulatory Care Reporting System to determine emergency department visits. We used the Home Care Database to determine dates of publically funded homecare service use and service type. Statistics Canada census data were used to determine region and rurality, using postal code data.

\section{Propensity score matching}

To reduce selection bias, we used propensity score matching to assemble a group of unexposed patients who were similar to each of the intervention groups. We created 11 matched cohorts, each consisting of pairs of exposed patients and unexposed subjects who were selected from an appropriate control population. The propensity score is each individual's probability of using a specialist team given the values of his pre-intervention, baseline covariates. Matching on the propensity score can estimate the effect of the intervention, which is unbiased by differences in measured pre-intervention covariates, thus aiming to simulate a randomised trial using observational data. ${ }^{29} 30$

We used the following baseline covariates (based on their association with use of acute care at end of life ${ }^{2031}$ ) to determine propensity scores:

Age at death

Sex (male or female)

Comorbidity weighting - We used the Johns Hopkins Adjusted Clinical Group method to adjust for comorbidity, which has been validated for use in Canadian populations. ${ }^{32}$ Adjusted Clinical Group uses each patient's age, sex, and inpatient and outpatient diagnosis codes to categorise patients into discrete groups-Adjusted Clinical Groups-where each group has similar healthcare need, morbidity, and expected resource consumption. We calculated Adjusted Clinical Groups using the period two months before death until 1.5 years before death. These Adjusted Clinical Groups are given a weight, based on expected resource use, relative to the average use of healthcare services of the population.

Cancer diagnosis-Cancer $v$ non-cancer, determined using the Adjusted Clinical Group Expanded Diagnostic Cluster method.

\section{Hospital and emergency department use before}

intervention - This consisted of three separate variables: mean number of hospitalisations, mean length of stay in hospital, and the number of emergency department visits during the period six months before death until 1.5 years before death.

Exposed and unexposed patients were matched on three variables:

Logit of the propensity score-We used callipers of width equal to 0.2 of the standard deviation of the logit of the propensity score, in keeping with prior research. ${ }^{33}{ }^{34} \mathrm{We}$ estimated the propensity score using a logistic regression model with exposure to a specialist team as the independent variable. Predictor variables were the baseline covariates described above.

Region and time-As described above, teams formed after 2009 were matched in the same region but a different time (fiscal years 2007-09), whereas teams formed before 2009 were matched in a different region but the same time.

Homecare service type and time in homecare-We matched so that when homecare was used, the pair received the same homecare service type and intent (ranging from end of life (death expected within six months) to rehabilitation/acute (full recovery expected)) and for the same amount of time before death (matched within two weeks of the first identified homecare service date of the exposed patient in the year before death).

\section{Outcomes}

The dichotomous outcomes were $(a)$ being in hospital in the last two weeks of life, $(b)$ having an emergency department visit in the last two weeks of life, and (c) dying in hospital (that is, in an inpatient unit). These outcomes are common in palliative care research and are widely used population-level indicators of poor quality because they indicate over-aggressive care. ${ }^{35}$

\section{Analytic approach}

We estimated the relative risk of using acute care in the last two weeks of life and dying in hospital in each of the 11 teams separately and also the overall pooled effect (weighted). Methods appropriate for matched samples were used in all cases (for example, McNemar's test for binary outcomes). ${ }^{346} \mathrm{We}$ conducted a sensitivity analysis to examine separately the pooled results for the two approaches (historical and geographical) used to identify a control group. Analysis was completed using statistical software SAS v9. The study was approved by McMaster University's research ethics board.

\section{Results}

Our results showed variation across the 11 specialist palliative care teams in terms of team size, geographies served, and number of deaths in the catchment area (table $1 \Downarrow$ ). Admissions during fiscal years 2009-11 ranged from 90 to 830 patients across the 11 teams. Team compositions varied as well: the number of full time equivalent palliative care physicians per team ranged from 0.5 to 11.5 , and the number of nurses ranged 
from 1 to 8 . The overall mean time from admission to a specialist palliative care team to death was 73 days (standard deviation 92 days).

The 11 specialist teams overall served 3912 patients who died during fiscal years 2009-11 (exposed group), whereas the control regions had 41133 deaths (unexposed group) (table $2 \Downarrow$ ). The characteristics of the initial exposed and unexposed groups differed greatly. For example, $79 \%$ of the exposed group had cancer compared with $35 \%$ of the unexposed group $(\mathrm{P}<0.001)$. Similarly, $78 \%$ of the exposed group received end of life homecare services compared with $15 \%$ of the unexposed group $(\mathrm{P}<0.001)$.

After propensity score matching, 3109 exposed patients were matched to 3109 unexposed patients, and the characteristics of these two groups were nearly identical: in both groups about $80 \%$ had cancer and $95 \%$ received some kind of homecare service in the last year of life ( $78 \%$ received end of life homecare services specifically, with similar mean time from first end of life homecare service to death). Therefore, after propensity score matching, the only observed systematic difference between the two groups was their exposure to a specialist team.

Our pooled results show that $970(31.2 \%)$ of the exposed group was in hospital in the last two weeks of life compared with 1219 $(39.3 \%)$ of the unexposed group $(\mathrm{P}<0.001)$. The pooled relative risk of being in hospital in the last two weeks of life for exposed versus unexposed patients was 0.68 (95\% confidence interval 0.61 to 0.76 ), and six of the 11 specialist palliative care teams had significantly lower relative risks (fig $1 \Downarrow$ ). Similarly our pooled results show that $896(28.9 \%)$ of the exposed group had an emergency department visit in the last two weeks of life compared with $1070(34.5 \%)$ of the unexposed group $(\mathrm{P}<0.001)$. The pooled relative risk of having an emergency department visit in the last two weeks of life was 0.77 (0.69 to 0.86), and four of the 11 teams had significantly lower relative risk (fig $2 \Downarrow)$. Finally, across all teams fewer exposed patients died in hospital compared with unexposed patients (503 (16.2\%) v 887 $(28.6 \%), \mathrm{P}<0.01)$. The pooled relative risk of dying in hospital for exposed versus unexposed groups was 0.46 (0.40 to 0.52 ), and nine of the 11 teams had significantly lower relative risk (fig $3 \Downarrow$ ). The sensitivity analysis found consistent results between the two approaches used to identify a control group (historical and geographical) with the pooled results reported above.

\section{Discussion}

\section{Principal findings}

Our pooled analysis of 11 specialist palliative care team interventions strongly suggests that exposure to a palliative care specialist team compared with usual care significantly reduces the risk of being in hospital and going to an emergency department in the last two weeks of life by a third and a quarter respectively, and reduces the risk of dying in hospital by half. These results suggest that even in real world, non-controlled settings, with multiple differences between the specialist teams and the geographies they serve, the core of the intervention (nurses, palliative care physicians, and family physicians working together to enhance usual palliative home care) significantly reduces the use of acute care services in late life and allows patients to die outside of hospital.

\section{Strengths and limitations of the study}

This study capitalised on a natural experiment in Ontario, Canada, where multiple communities independently developed specialist palliative care teams that differed in geography, team size, and team organisation but had the same core team members with the same roles as prior randomised trials. Thus, a key contribution of this research was to explore whether the core elements of the randomised trials would be effective at reducing use of acute care, even when implemented with different team compositions, while keeping the health system constant. A unique strength of our study was the use of propensity score matching in our observational data to reduce selection bias in the control group. Pooling our data also allowed for a large sample size and sufficient power, which was a limitation of some previous trials.

Our study is limited in that propensity scores cannot adjust for unmeasured covariates, such as patient preferences for hospital care and availability of existing care giver support. Teams were selected because their regions did not have major changes to the palliative care health system during the comparison period, though it is impossible to claim no changes at all. This study's teams served primarily cancer patients, which limits the generalisability of the intervention effect to teams primarily serving another disease group.

\section{Comparison with other studies}

Several trials have examined one community based palliative care intervention using different team compositions, outcomes, and health financing systems ${ }^{9-17}$ making it difficult to compare and generalise; whereas our pooled analysis compared 11 teams with different team compositions but using common outcomes in the same healthcare financing system. Moreover, our pooled study design supports the generalisability of the evidence that community based specialist teams are effective at reducing acute care use at the end of life in other countries. Despite different healthcare financing policies, international research has documented the same issues with end of life care in healthcare systems as those documented in the "usual care" system in Ontario: communication problems between settings and providers, inadequate symptom control, unmet psychological needs, and late referrals to specialist palliative care. ${ }^{19}{ }^{37}$

The intervention's effect likely results from the fact that—unlike usual care at home, where palliative care providers vary considerably in their accessibility, palliative care training, and ability to coordinate care- the specialist palliative care team can help to eliminate the variation and ensure that care is accessible, coordinated, and provided by skilled workers. We believe that the common features of the teams we studied (such as 24/7 coverage and collaboration between nurses, specialist physicians, and family physicians) are not unique to the Canadian system and have similarities to existing models in other countries. Compared with the UK, the community based specialist palliative care teams in Ontario have similarities to palliative care professionals working with hospice at home services and palliative care specialist nurses (such as Marie Curie nurses), as well as primary care teams using the Gold Standard Framework. ${ }^{27}$ Indeed, our results are consistent with observational work undertaken in the UK. ${ }^{38}$ Compared with the US, the teams resemble home based, visiting hospice programmes under the Medicare Hospice Benefit, though patients in the Ontario do not need to forego other treatment for their terminal illness to access the community specialist teams, which is required in the US. ${ }^{39}$

\section{Policy implications and conclusions}

What services does the core team of providers deliver to patients and families that helps reduce use of acute care services late in 
life? Care from the teams may help avoid unplanned use by anticipating clinical problems early and making care arrangements in advance. Teams expertly manage, monitor, and rapidly respond to complex symptoms and changes in the patient's condition. When needed to support the patient or prevent care giver burnout, they directly provide care or advocate for additional care. Moreover, patients and families can access the teams 24/7, a feature especially important on evenings and weekends, when usual care provider's offices are typically closed. Indeed research shows that emergency department visits and hospitalisations late in life occur because of inadequate symptom control and failure to cope, among other factors. ${ }^{40}$

Of the 11 specialist teams in our study, two (teams 5 and 6) did not have any significant results across the outcomes, which could indicate an ineffective intervention. For example, team 5 had a small team and a part time palliative care physician. Team 6 covered a large, rural area with a small team. However, the non-significant results may also be due to the small sample sizes for individual teams. Four teams (teams 4, 7, 9, and 11) showed significantly positive effects of the intervention across all outcomes despite their number of admissions, teams size, and geography served varied considerably. This result emphasises the importance of the core services the teams provided, which was common across all teams, rather than the team composition or model in which they practiced. The remaining teams demonstrated significantly positive outcomes for one or two outcomes, though we could not determine if acute care use in the non-significant outcomes were medically appropriate.

\section{Conclusions}

Using propensity scores to simulate a randomised trial of a specialist palliative care team intervention, our pooled analysis suggests that even in real world, non-controlled settings, where specialist teams vary in team composition and geography served, the specialist team intervention supports more patients to die outside of hospitals and avoid late-life use of acute services compared with usual care. The impact of specialist team interventions on the various non-cancer diagnoses in the community should be investigated further. Future research should also determine the intervention's impact on other health system outcomes, such as primary care capacity or patient and provider satisfaction, as well as assess how the variation among teams (such as role of additional team members or models of care) are associated with these outcomes.

Contributors: All authors were involved in either the study design, data acquisition, or data analysis; and all authors were involved in interpretation of data and writing of the manuscript, and take responsibility for the integrity of the data and the accuracy of the data analysis.

Funding: This study was funded by a grant from the Canadian Institutes of Health Research (No 115112) and used databases maintained by the Institute for Clinical Evaluative Sciences, which receives funding by the Ontario Ministry of Health and Long term Care. The opinions, results, and conclusions reported in this paper are those of the authors and are independent from the funding sources.

Competing interests: All authors have completed the ICMJE uniform disclosure form at www.icmje.org/coi_disclosure.pdf (available on request from the corresponding author) and declare: three authors $(\mathrm{AH}$, JP, DM) are physicians in three of the palliative care teams and provided access to data, but were not involved in the data analysis; the remaining authors have no financial relationships with any organisations that might have an interest in the submitted work in the previous three years; no other relationships or activities that could appear to have influenced the submitted work.

Ethical approval: The study was approved by McMaster University's research ethics board.

Data sharing: No additional data available.

Transparency: The lead author, HS, affirms that the manuscript is honest, accurate, and transparent account of the study being reported; no important aspects of the study have been omitted; and any discrepancies from the study as planned have been explained.

1 Carr D, Goudas L, Lawrence D, Pirl W, Lau J, DeVine D, et al. Management of cancer symptoms: pain, depression, and fatigue. Evidence report/technology assessment No 61 (AHRQ Publication No 02-E032.) Agency for Healthcare Research and Quality, 2002.

2 Covinsky KE, Fortinsky RH, Palmer RM, Kresevic DM, Landefeld CS. Relation between symptoms of depression and health status outcomes in acutely ill hospitalized older persons. Ann Intern Med 1997;126:417-25.

3 Fassbender K, Fainsinger RL, Carson M, Finegan BA. Cost trajectories at the end of life: the Canadian experience. J Pain Symptom Manage 2009;38:75-80.

4 Higginson IJ, Sen-Gupta GJ. Place of care in advanced cancer: a qualitative systematic literature review of patient preferences. J Palliat Med 2000;3:287-300.

5 Paz-Ruiz S, Gomez-Batiste X, Espinosa J, Porta-Sales J, Esperalba J. The costs and savings of a regional public palliative care program: the Catalan experience at 18 years. $J$ Pain Symptom Manage 2009;38:87-96.

6 Hearn J, Higginson IJ. Do specialist palliative care teams improve outcomes for cancer patients? A systematic literature review. Palliat Med 1998:12:317-32.

7 Higginson IJ, Finlay IG, Goodwin DM, Hood K, Edwards AG, Cook A, et al. Is there evidence that palliative care teams alter end-of-life experiences of patients and their caregivers? J Pain Symptom Manage 2003;25:150-68.

8 Higginson IJ, Evans CJ. What is the evidence that palliative care teams improve outcomes for cancer patients and their families? Cancer $J$ 2010;16:423-35.

9 Aiken LS, Butner J, Lockhart CA, Volk-Craft BE, Hamilton G, Williams FG. Outcome evaluation of a randomized trial of the PhoenixCare intervention: program of case management and coordinated care for the seriously chronically ill. $J$ Palliat Med management and $2006 ; 9: 111-26$.

10 Brumley R, Enguidanos S, Jamison P, Seitz R, Morgenstern N, Saito S, et al. Increased satisfaction with care and lower costs: results of a randomized trial of in-home palliative care. J Am Geriatr Soc 2007:55:993-1000.

11 Hughes SL, Cummings J, Weaver F, Manheim L, Braun B, Conrad K. A randomized trial of the cost effectiveness of VA hospital-based home care for the terminally ill. Health Serv Res 1992;26:801-17.

12 Hughes SL, Weaver FM, Giobbie-Hurder A, Manheim L, Henderson W, Kubal JD, et al; Department of Veterans Affairs Cooperative Study Group on Home-Based Primary Care. Effectiveness of team-managed home-based primary care: a randomized multicenter trial. JAMA 2000;284:2877-85.

13 Jordhøy MS, Fayers P, Saltnes T, AhIner-Elmqvist M, Jannert M, Kaasa S. A palliative-care intervention and death at home: a cluster randomised trial. Lancet 2000;356:888-93.

14 Rabow MW, Dibble SL, Pantilat SZ, McPhee SJ. The comprehensive care team: a controlled trial of outpatient palliative medicine consultation. Arch Intern Med 2004:164:83-91.

15 Zimmer JG, Groth-Juncker A, McCusker J. A randomized controlled study of a home health care team. Am J Public Health 1985;75:134-41.

16 Bakitas M, Lyons KD, Hegel MT, Balan S, Brokaw FC, Seville J, et al. Effects of a palliative care intervention on clinical outcomes in patients with advanced cancer: the Project ENABLE II randomized controlled trial. JAMA 2009;302:741-9.

17 Higginson IJ, McCrone P, Hart SR, Burman R, Silber E, Edmonds PM. Is short-term palliative care cost-effective in multiple sclerosis? A randomized phase II trial. J Pain Symptom Manage 2009;38:816-26.

18 Luckett T, Davidson PM, Lam L, Phillips J, Currow DC, Agar M. Do community specialist palliative care services that provide home nursing increase rates of home death for people with life-limiting illnesses? A systematic review and meta-analysis of comparative studies. J Pain Symptom Manage 2013;45:279-97.

19 Carstairs S. Still not there. In: Quality end-of-life care: a progress report. Senate of Canada, 2005: 1-52.

20 Seow H, Barbera L, Howell D, Dy SM. Using more end-of-life homecare services is associated with using fewer acute care services: a population-based cohort study. Med Care 2010;48:118-24

21 Sussman J, Barbera L, Bainbridge D, Howell D, Yang J, Husain A, et al. Health system characteristics of quality care delivery: a comparative case study examination of palliative care for cancer patients in four regions in Ontario, Canada. Palliat Med 2012;26:322-35.

22 Barbera L, Sussman J, Viola R, Husain A, Howell D, Librach SL, et al. Factors associated with end-of-life health service use in patients dying of cancer. Healthc Policy 2010;5:e125-43.

23 Seow H, Barbera L, Howell D, Dy SM. How end-of-life home care services are used from admission to death: a population-based cohort study. J Palliat Care 2010;26:270-8.

24 Marshall D, Howell D, Brazil K, Howard M, Taniguchi A. Enhancing family physician capacity to deliver quality palliative home care: an end-of-life, shared-care model. Can Fam Physician 2008;54:1703, e7.

25 Almaawiy U, Pond GR, Sussman J, Brazil K, Seow H. Are family physician visits and continuity of care associated with acute care use at end-of-life? A population-based cohort study of homecare cancer patients. Palliat Med 2014;28:176-83.

26 Statistics Canada. Table 102-0509. Deaths in hospital and elsewhere, Canada, provinces, and territories. 2013.

27 Gray BH. England's approach to improving end-of-life care: a strategy for honoring patients' choices. Issue Brief (Commonw Fund) 2011;15:1-15.

28 World Health Organization. In: Davies E, Higginson I, eds. The solid facts: palliative care .WHO, 2004.

29 Rosenbaum P, Rubin D. The central role of the propensity score in observational studies for causal effects. Biometrika 1983;70:41-55. 


\section{What is already known on this topic}

Several randomised trials of community based, specialist palliative care teams have produced mixed evidence as to their efficacy to reduce late life use of acute care and hospital deaths

Team size and composition varied in the trials, which may explain the variation in acute care use, but this has not been studied

\section{What this study adds}

A pooled analysis of 11 community based, palliative care teams strongly suggests that-despite variation in team size, composition, and geography served-exposure to the specialist team intervention compared with usual care significantly reduces the risk of: being in hospital (relative risk $0.68(95 \% \mathrm{Cl} 0.61$ to 0.76$)$ ) or having an emergency department visit (relative risk $0.77(0.69$ to 0.86$))$ in the last two weeks of life and of dying in hospital (relative risk $0.46(0.40$ to 0.52$))$

30 Rosenbaum P, Rubin D. Constructing a control group using multivariate matched sampling methods that incorporate the propensity score. Am Stat 1985;39:33-8.

31 Gomes B, Higginson IJ. Factors influencing death at home in terminally ill patients with cancer: systematic review. BMJ 2006;332:515-21.

32 Sibley LM, Moineddin R, Agha MM, Glazier RH. Risk adjustment using administrative data-based and survey-derived methods for explaining physician utilization. Med Care 2010;48:175-82.

33 Austin PC. Balance diagnostics for comparing the distribution of baseline covariates between treatment groups in propensity-score matched samples. Stat Med 2009;28:3083-107.

34 Austin PC, Type I. Type I error rates, coverage of confidence intervals, and variance estimation in propensity-score matched analyses. Int J Biostat 2009;5:13.

35 Earle CC, Park ER, Lai B, Weeks JC, Ayanian JZ, Block S. Identifying potential indicators of the quality of end-of-life cancer care from administrative data. J Clin Oncol 2003;21:1133-8.

36 Austin PC. A critical appraisal of propensity-score matching in the medical literature between 1996 and 2003. Stat Med 2008;27:2037-49.
37 Healthcare Commission. Spotlight of complaints: A report on second-stage complaints about NHS in England. Healthcare Commission, 2009.

38 Pocock L, Wye L, Purdy S. A qualitative study to evaluate the process of identifying patients at the end-of-life in primary care. BMJ Support Palliat Care 2014;4:105.

39 US Code of Federal Regulations. Hospice care. Title 42, Section 418.1. 2000.

40 Barbera L, Taylor C, Dudgeon D. Why do patients with cancer visit the emergency department near the end of life? CMAJ 2010;182:563-8.

Accepted: 12 May 2014

\section{Cite this as: BMJ 2014;348:g3496}

This is an Open Access article distributed in accordance with the Creative Commons Attribution Non Commercial (CC BY-NC 3.0) license, which permits others to distribute, remix, adapt, build upon this work non-commercially, and license their derivative works on different terms, provided the original work is properly cited and the use is non-commercial. See: http://creativecommons.org/licenses/by-nc/3.0/. 


\section{Tables}

Table 1/ Characteristics of the 11 palliative care teams in study

\begin{tabular}{|c|c|c|c|c|c|c|c|c|}
\hline \multirow[b]{2}{*}{ Team } & \multirow[b]{2}{*}{$\begin{array}{l}\text { No of deaths in } \\
\text { comparison } \\
\text { region in 2009-11 }\end{array}$} & \multirow{2}{*}{$\begin{array}{c}\text { No of } \\
\text { admissions to } \\
\text { team in } \\
2009-11\end{array}$} & \multirow[b]{2}{*}{$\begin{array}{c}\text { No }(\%) \text { of rural } \\
\text { admissions to } \\
\text { team }{ }^{\star}\end{array}$} & \multirow[b]{2}{*}{$\begin{array}{l}\text { Date team } \\
\text { established }\end{array}$} & \multirow[b]{2}{*}{$\begin{array}{l}\text { Mean (SD) time in } \\
\text { team's care before } \\
\text { death (days) }\end{array}$} & \multicolumn{3}{|c|}{ No of full time equivalent team members } \\
\hline & & & & & & $\begin{array}{l}\text { Palliative care } \\
\text { physicians }\end{array}$ & Nurses & Other† \\
\hline 1 & 16243 & 830 & $\leq 5(0.6)$ & 2009 & $68(79)$ & 1 & 8 & 2 \\
\hline 2 & 2240 & 221 & $\leq 5(0.9)$ & 2009 & $97(117)$ & 1 & 2 & 1.5 \\
\hline 3 & 1534 & 144 & $9(6.3)$ & 2009 & $83(102)$ & 1 & 1 & 0.6 \\
\hline 4 & 1670 & 125 & $\leq 5(3.2)$ & 2009 & $66(86)$ & 1 & 2 & 1 \\
\hline 5 & 3102 & 105 & $\leq 5(1.9)$ & 2009 & $72(85)$ & 0.5 & 1 & 0.2 \\
\hline 6 & 1185 & 90 & $58(64.4)$ & 2009 & $93(97)$ & 2 & 2 & 1.2 \\
\hline 7 & 7629 & 676 & $\leq 5(0.1)$ & 1986 & $71(83)$ & 11.5 & 1 & 5.9 \\
\hline 8 & 5264 & 497 & $41(8.2)$ & 2007 & $82(93)$ & 2 & 2 & 1 \\
\hline 9 & 840 & 775 & $100(12.9)$ & 1998 & $73(98)$ & 1.3 & 3 & 1.7 \\
\hline 10 & 737 & 268 & $36(13.4)$ & 2004 & $60(96)$ & 0.6 & 1 & 2.5 \\
\hline 11 & 689 & 181 & $66(36.5)$ & 1979 & $63(102)$ & 6 & 2 & 4.7 \\
\hline Pooled & 41133 & 3912 & 324 (8.3) & $\mathrm{N} / \mathrm{A}$ & $73(92)$ & $\mathrm{N} / \mathrm{A}$ & $\mathrm{N} / \mathrm{A}$ & $\mathrm{N} / \mathrm{A}$ \\
\hline
\end{tabular}

${ }^{*}$ Community population $<10000$.

tOther team members vary by team, including psychosocial worker, bereavement counselor, social worker, administrative support, etc. 
Table 2| Characteristics of patients served by 11 specialist palliative care teams (exposed) and patients who received usual care (unexposed) before and after propensity score matching. Values are numbers (percentages) of patients unless stated otherwise

\begin{tabular}{|c|c|c|c|c|}
\hline \multirow[b]{2}{*}{ Characteristics } & \multicolumn{2}{|c|}{ Before propensity score matching } & \multicolumn{2}{|c|}{ After propensity score matching } \\
\hline & Exposed & Unexposed & Exposed & Unexposed \\
\hline No of patients (pooled across the teams) & 3912 & 41133 & 3109 & 3109 \\
\hline Median (IQR) age at death (years) & 75 (64 to 84$)$ & 80 (69 to 87 ) & 75 (64 to 84$)$ & 74 (63 to 83 ) \\
\hline Cancer diagnosis & $3073(78.6)$ & $14443(35.1)$ & $2469(79.4)$ & $2481(79.8)$ \\
\hline Women & $2032(51.9)$ & $20895(50.8)$ & $1600(51.5)$ & $1609(51.8)$ \\
\hline Men & $1880(48.1)$ & $20238(49.2)$ & $1509(48.5)$ & $1500(48.2)$ \\
\hline Mean (SD) adjusted clinical group comorbidity weighting & $6.30(4.04)$ & $5.12(4.09)$ & $6.20(3.98)$ & $6.21(3.93)$ \\
\hline \multicolumn{5}{|l|}{ Home care service type: } \\
\hline End of life & $3041(77.7)$ & $6208(15.1)$ & $2409(77.5)$ & $2409(77.5)$ \\
\hline Long term supportive & $210(5.4)$ & $3408(8.3)$ & $145(4.7)$ & $145(4.7)$ \\
\hline Maintenance & $328(8.4)$ & $7692(18.7)$ & $278(8.9)$ & $278(8.9)$ \\
\hline Rehabilitation or acute care & $157(4.0)$ & $6478(15.7)$ & $106(3.4)$ & $106(3.4)$ \\
\hline None & $176(4.5)$ & $17347(42.2)$ & $171(5.5)$ & $171(5.5)$ \\
\hline \multicolumn{5}{|c|}{$\begin{array}{l}\text { Mean (SD) time from first receipt of most severe home care service type } \\
\text { (days before death): }\end{array}$} \\
\hline End of life & $86.18(107.29)$ & $15.47(56.48)$ & $79.32(102.05)$ & $79.23(102.02)$ \\
\hline Long term supportive & $31.00(87.25)$ & $23.92(81.17)$ & $27.84(83.51)$ & $37.96(95.92)$ \\
\hline Maintenance & $82.02(131.69)$ & $63.68(124.80)$ & $83.55(132.16)$ & $81.64(131.06)$ \\
\hline Rehabilitation or acute care & $76.05(113.98)$ & $69.70(113.27)$ & $80.12(114.96)$ & $79.29(112.60)$ \\
\hline Mean (SD) No of prior emergency department visits & $1.43(2.11)$ & $1.16(2.10)$ & $1.36(1.96)$ & $1.40(1.95)$ \\
\hline Mean (SD) prior hospital length of stay (days) & $7.53(17.09)$ & $7.18(22.23)$ & $6.73(14.85)$ & $6.84(14.17)$ \\
\hline Mean (SD) No of prior hospital visits & $0.75(1.14)$ & $0.56(1.04)$ & $0.70(1.07)$ & $0.76(1.15)$ \\
\hline \multicolumn{5}{|l|}{ Income quintile*: } \\
\hline 1 (lowest) & $668(17.1)$ & $10288(25.0)$ & $536(17.2)$ & $772(24.8)$ \\
\hline 2 & $746(19.1)$ & $9053(22.0)$ & $605(19.5)$ & $703(22.6)$ \\
\hline 3 & $720(18.4)$ & $7565(18.4)$ & $550(17.7)$ & $604(19.4)$ \\
\hline 4 & $872(22.3)$ & $7460(18.1)$ & $675(21.7)$ & $585(18.8)$ \\
\hline 5 (highest) & $906(23.2)$ & $6555(15.9)$ & $743(23.9)$ & $437(14.1)$ \\
\hline
\end{tabular}

${ }^{*}$ Community income quintiles were reported from Census data using postal codes. 


\section{Figures}

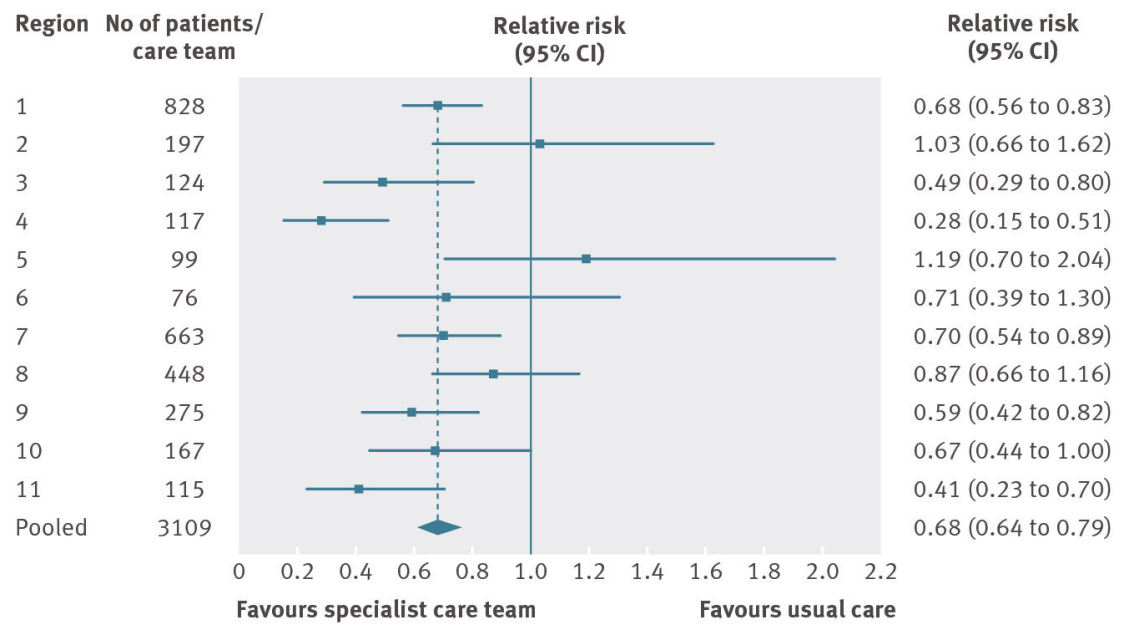

Fig 1 Relative risk of being in hospital in the last two weeks of life for exposed patients (care from specialist palliative care team) and unexposed patients (usual care)

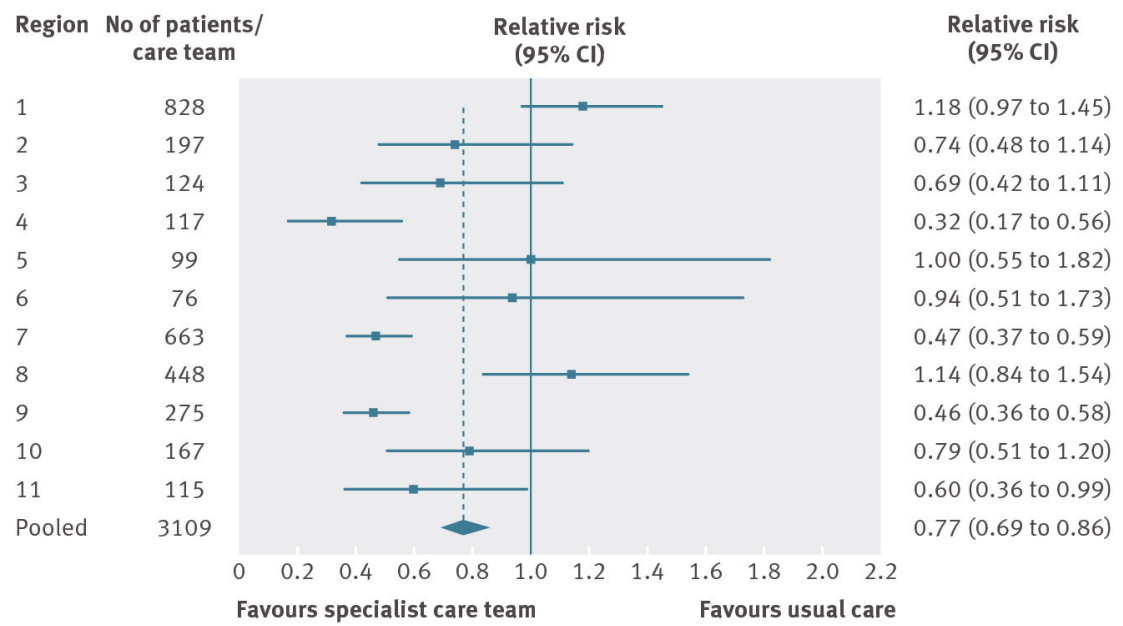

Fig 2 Relative risk of an emergency department visit in the last two weeks of life for exposed patients (care from specialist palliative care team) and unexposed patients (usual care) 


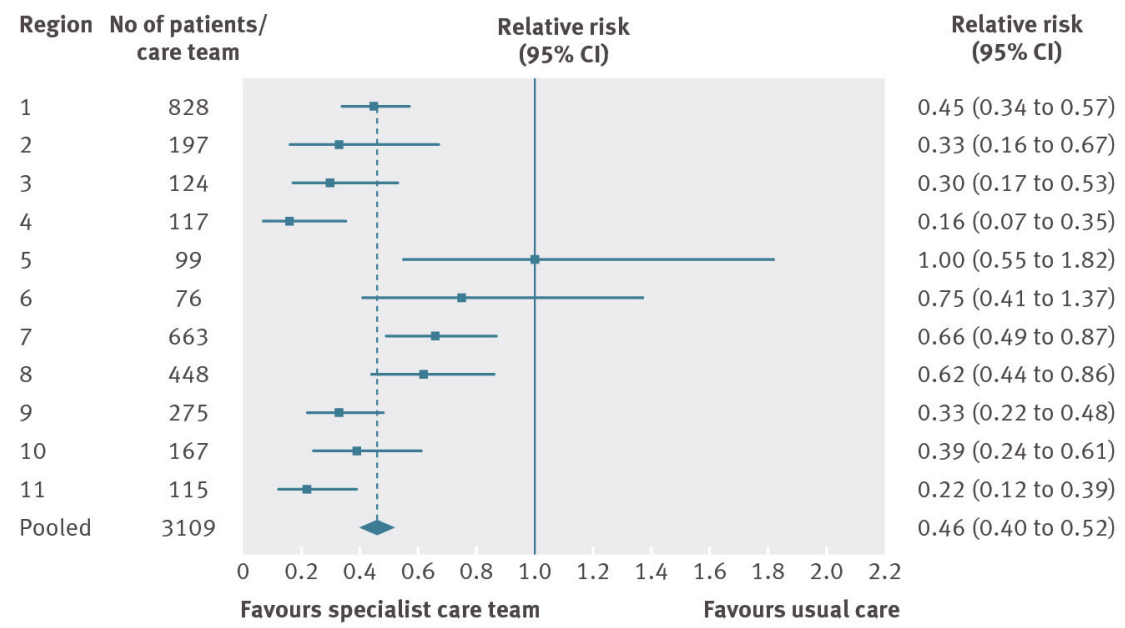

Fig 3 Relative risk of dying in hospital for exposed patients (care from specialist palliative care team) and unexposed patients (usual care) 